Being Different Yet Feeling Similar: The Influence of Demographic Composition and Organizational Culture on Work Processes and Outcomes

Author(s): Jennifer A. Chatman, Jeffrey T. Polzer, Sigal G. Barsade and Margaret A. Neale

Source: Administrative Science Quarterly, Vol. 43, No. 4 (Dec., 1998), pp. 749-780

Published by: Sage Publications, Inc. on behalf of the Johnson Graduate School of Management, Cornell University

Stable URL: http://www.jstor.org/stable/2393615

Accessed: 26-02-2015 20:52 UTC

Your use of the JSTOR archive indicates your acceptance of the Terms \& Conditions of Use, available at http://www.jstor.org/page/info/about/policies/terms.jsp

JSTOR is a not-for-profit service that helps scholars, researchers, and students discover, use, and build upon a wide range of content in a trusted digital archive. We use information technology and tools to increase productivity and facilitate new forms of scholarship. For more information about JSTOR, please contact support@jstor.org.

Sage Publications, Inc. and Johnson Graduate School of Management, Cornell University are collaborating with JSTOR to digitize, preserve and extend access to Administrative Science Quarterly. 


\section{Being Different Yet Feeling Similar: The Influence of Demographic Composition and Organizational Culture on Work Processes and Outcomes}

\author{
Jennifer A. Chatman \\ University of California, \\ Berkeley \\ Jeffrey T. Polzer \\ University of Texas, Austin
}

Sigal G. Barsade

Yale University

Margaret A. Neale

Stanford University

(C) 1998 by Cornell University. 0001-8392/98/4304-0749/\$1.00.

This research was supported by a Cente for Creative Leadership grant to the first author. We thank Dan Brass, Ben Hermalin, Rod Kramer, and three anonymous reviewers for helpful comments on earlier drafts of the paper, and Linda Johanson for working her usual editorial magic. We also thank Zoe Barsness, Joe Baumann, Mary Cusack, Brenda Ellington, Tiffany Galvin, Anne Lytle, Ann Tenbrunsel, Melissa Thomas-Hunt, and Kim

Wade-Benzoni for help in administering the study.
Drawing from self-categorization theory, we tested hypotheses on the effects of an organization's demographic composition and cultural emphasis on work processes and outcomes. Using an organizational simulation, we found that the extent to which an organization emphasized individualistic or collectivistic values interacted with demographic composition to influence social interaction, conflict, productivity, and perceptions of creativity among $258 \mathrm{MBA}$ students. Our findings suggest that the purported benefits of demographic diversity are more likely to emerge in organizations that, through their culture, make organizational membership salient and encourage people to categorize one another as having the organization's interests in common, rather than those that emphasize individualism and distinctiveness among members.

Research generated from a variety of fields predicts that important benefits will accrue from demographic heterogeneity in organizations by increasing the variance in perspectives and approaches to work that members of different identity groups can bring (e.g., Thomas and Ely, 1996). For example, cognitive and experiential diversity may add to the perspectives available within an organization and facilitate clarifying, organizing, and combining novel approaches to accomplishing goals (e.g., Hoffman and Maier, 1961). Further, work units composed of diverse members can tap into broad networks of contacts, making it likely that useful new information will be incorporated into decisions, which can increase commitment to choices and enhance responsiveness to rapidly changing organizational environments (Tushman, 1977; Donnellon, 1993).

Managers' attempts to capitalize on these advantages have met with mixed success (e.g., Heilman, 1994). Research on the effects of demographic diversity in organizations has also been characterized by mixed findings (Watson, Kumar, and Michaelsen, 1993), leading Guzzo and Dickson (1996: 331) to conclude that, in spite of its recent popularity, there is little consensus about either what constitutes diversity or how it affects performance. According to some researchers, demographic heterogeneity seems to be beneficial, supporting a "value-in-diversity" hypothesis (Cox, Lobel, and McLeod, 1991: 827); but others have found diversity to be detrimental to work effectiveness (see Williams and O'Reilly, 1998, for a review). For example, heterogeneous work groups have been found to be less socially integrated and to have experienced more communication problems, more conflict, and higher turnover rates than homogeneous groups (O'Reilly, Caldwell, and Barnett, 1989; Zenger and Lawrence, 1989). Further, people who were more different from their coworkers in terms of age, tenure, education, sex, and race have reported feeling more uncomfortable and less attached to their employing organization (Tsui, Egan, and O'Reilly, 1992).

We attempt to resolve some of these contradictions by considering how differences in organizational cultures moderate how demographically diverse people approach and solve problems. An organization's relative focus on individualism or collectivism may affect the salience of organizational mem- 
bership as a social category and, as a result, coworkers' perceptions of having interchangeable interests and a common fate. We begin by exploring how being demographically similar to or different from coworkers and an organization's emphasis on individualism or collectivism uniquely and jointly influence the self-categorization process.

\section{Self-Categorization, Demographic Composition, and Individualistic Versus Collectivistic Values}

Self-categorization refers to the process by which people define their self-concept in terms of their memberships in various social groups. It can be situationally based, because different aspects of a person's self-concept may become salient in response to the distribution of characteristics of others who are present in a situation (Markus and Cross, 1990). A salient social category is defined as one that functions psychologically to influence a person's perception and behavior and how others treat the focal individual (Turner et al., 1987). To the extent that a particular in-group membership is salient, one's perceived similarity to others in the ingroup is increased (Brewer, 1979). Increasing the salience of in-group membership causes a depersonalization of the self, defined as perceiving oneself as an interchangeable exemplar of the social category (Turner, 1985: 99). Members of a salient in-group are more likely to cooperate with in-group members and to compete against out-group members (e.g., Wagner, Lampen, and Syllwasschy, 1986).

An organization relies on members to cooperate with one another in accomplishing goals to enhance its survival (Simon, 1976: 72). Since one way to enhance cooperation is to increase the extent to which members view one another as part of their in-group, identifying the factors that cause people to categorize some people as in-group members and others as out-group members becomes important. Two of these factors may be the presence of demographic diversity among employees and an organization's cultural emphasis on individualism or collectivism.

Basing salient social categories on demographic attributes. People frequently use demographic characteristics to categorize others and predict their likely behaviors. Allport (1954) observed that immediately apparent physical features, such as race and sex, are widely used to form impressions of others (see also, Messick and Mackie, 1989). This tendency may be even more pronounced when demographic diversity is historically or normatively uncommon in a situation, because novel, infrequent, or distinctive stimuli are likely to increase the salience of the particular category that the stimuli represents (Kanter, 1977; Taylor and Fiske, 1978). Demographic attributes also tend to be used as a basis for social categorization because demographically similar people are likely to share similar backgrounds and experiences.

They are more likely to have been treated similarly by others in the past and may therefore expect one another to understand and react to situations similarly (e.g., Pfeffer, 1983). As a result, demographic attributes are often assumed to be associated with underlying attributes, such as values, cognitive styles, or past experience. This implies that people will be more likely to use demographic attributes as social cat-

750/ASQ, December 1998 


\section{Being Different}

egories when they are demographically different from others in a situation and when that situation has typically not been characterized by demographic heterogeneity in the past, as in most U.S. business organizations. We therefore propose:

Proposition 1: People who are more demographically different from their coworkers will view demographic attributes as more salient than will people who are more similar to one another.

Basing social categories on an organization's emphasis on individualism or collectivism. An organization's culture may also influence which of its members' social categories are activated. Organizational culture, defined as the observable norms and values that characterize an organization, influences which aspects of its operations and its members become salient and how members perceive and interact with one another, approach decisions, and solve problems (Trice and Beyer, 1993; O'Reilly and Chatman, 1996). The organizational culture's emphasis on either individualism or collectivism may particularly influence the social categorization process.

Research has shown that the individualism-collectivism dimension, while often examined at the societal level, is also central to characterizing how work is conducted at the organizational level (Earley, 1993; Chatman and Barsade, 1995). Individualistic cultures focus on and reward achievements that can be attributed to a particular person. Emphasizing individualism causes people to focus on their own and others' unique abilities and characteristics-on what differentiates them from others. In contrast, the focus in collectivistic cultures is on shared objectives, interchangeable interests, and commonalties among members. Members of collectivistic cultures are more likely than those in individualistic cultures to agree about what constitutes correct action, behave according to the norms of the culture, and suffer or offer severe criticism for even slight deviations from norms (Triandis, 1995: 52). Because of the heightened priority placed on interdependence and cooperation, people in collectivistic organizational cultures may be more likely to use organizational membership as a basis for social categorization. In these collectivistically oriented organizations, simply being a member of the organization may be enough to qualify one as an ingroup member (e.g., Wagner, 1995). In contrast, more flexibility exists in how people are allowed to behave in individualistic cultures, reducing the salience of organizational membership compared with collectivistic cultures. We therefore propose:

Proposition 2: Members of collectivistic organizational cultures will view organizational membership as a more salient category than will members of individualistic organizations.

Since multiple social categories exist, one question is whether they can be activated simultaneously. Research supports an inverse relationship, labeled functional antagonism, between the salience of different categories. Functional antagonism predicts that as one category becomes more salient, others become less salient (e.g., Turner et al., 1994). In an organizational context, the notion of functional antagonism implies that when organizational membership is salient, demographic attributes will be less salient. Specifically, a collectivistic culture may increase the salience of or-

751/ASQ, December 1998 
ganizational membership as a social category, causing a corresponding decrease in the salience of demographic categories.

Overt connectedness, attending to others, and harmonious interdependence are neither assumed nor valued in individualistic cultures. Individuals maintain their independence from others by attending to the self and by discovering and expressing their unique inner attributes (Markus and Kitayama, 1991: 224). Because the organizational boundary connecting members to one another will not be so salient in individualistic cultures as in collectivistic cultures, an organizational emphasis on individualism will not cause demographic categories to be replaced as the primary basis for selfcategorization. An individualistic culture will not lead people to ignore the organizational boundary intentionally, but an individualistic focus may make the organizational boundary a less likely candidate for categorizing self and others. In the absence of a salient organization boundary, easily observed and distinctive demographic categories may play a more prominent role in determining category salience, as suggested in the following proposition:

Proposition 3: The salience of demographic attributes as social categories will be inversely related to the salience of organizational attributes as social categories.

The above propositions can be translated into testable hypotheses by considering how the extent to which people are demographically different from one another and an organization's emphasis on individualism or collectivism can affect work processes.

\section{Work Processes: Social Interaction and Conflict}

Social interaction. Being in a situation in which demographic diversity exists and individual achievement is valued increases one's tendency to categorize those who are demographically similar into an in-group and those who are demographically different into out-groups. People trust and interact with in-group members significantly more than out-group members (e.g., Brewer, 1979). But, since the pooling of diverse information yields many of the benefits of diversity (e.g., Gruenfeld et al., 1996), one of the fundamental challenges to increasing these benefits in organizations is to get people to recategorize demographically dissimilar people as in-group members to increase interaction and mutual trust.

Research has shown that people of the same nationality, racial background, or sex are more likely to associate with one another within organizations. Ibarra (1992), for example, found that men and women tended to form friendship and support ties with others of the same sex in an advertising firm. Even though people who are demographically different may have multiple perspectives that are valuable in approaching and solving problems (e.g., Jackson, 1992), these perspectives are less likely to emerge because of people's reluctance to interact with others who are demographically different and difficulties in communicating different perspectives when interaction does take place. This suggests the following hypothesis: 
Hypothesis 1a $(\mathrm{H} 1 \mathrm{a})$ : Organizational members who are less demographically similar to their coworkers will interact less frequently when working on tasks than will members who are more demographically similar.

An organization's cultural emphasis on individualism or collectivism may also influence interaction among members. Feelings of similarity and of a common fate among members cultivated in collectivistic cultures lead members to consider more of their coworkers to be part of their in-group. Because in-group members seek out and prefer to interact with one another, members of organizations emphasizing collectivistic values should interact with one another and participate in joint efforts to solve organizational problems more frequently than would members of individualistic organizations:

Hypothesis $1 b(\mathrm{H} 1 \mathrm{~b})$ : Members of organizations that emphasize collectivistic values will interact more frequently when working on tasks than will members of organizations emphasizing individualistic values.

Perhaps most important, however, an organization's emphasis on either individualistic or collectivistic values may moderate how extensively demographic dissimilarity influences interaction among people. Members of individualistic cultures who are demographically different from their coworkers may be reluctant to interact with one another because in-group and out-group assignments are based on demographic categories. Demographically similar people, in contrast, may categorize one another as in-group members because of their common demographic attributes, even in individualistic cultures. In effect, the organizational boundary and demographic category memberships completely overlap in organizations with demographically similar members. This overlap makes the organizational boundary almost redundant in its capacity to define an in-group in which all organizational members share membership and to influence interaction among organizational members. Because they are likely to categorize the same set of organizational members as the in-group, regardless of whether the organization or demographic attributes are used as the basis for categorization, demographically similar people should be less affected than dissimilar people by whether the organizational culture emphasizes individualism or collectivism. For demographically diverse people, categorizing organizational members into a common in-group may displace categorizing many of these same people into out-groups based on demographic differences (Wilder, 1986). Interaction among demographically dissimilar people, however, should be higher in collectivistic cultures than in individualistic cultures because more organizational members are perceived as part of the in-group in the former. More formally, we predict the following:

Hypothesis 1c $(\mathrm{H} 1 \mathrm{c})$ : People who are more demographically different from their coworkers will interact with one another significantly more frequently when their organizational culture emphasizes collectivism than when it emphasizes individualism, while members who are more demographically similar to one another will interact with one another with the same frequency regardless of the emphasis of their organizational culture.

Since we focus on understanding the effects of demographic diversity and culture on an array of work processes and outcomes that may be influenced by how frequently co- 
workers interact with one another and interaction among members may vary, we control for the influence of coworker interaction in subsequent hypotheses.

Conflict. Once people begin interacting with one another to accomplish tasks, effectiveness is determined by the quality of this interaction. Conflict is an important indicator of the quality of interaction and can be defined as perceived incompatibilities or perceptions by the parties involved that they hold discrepant views (Boulding, 1963). Diverse employees have the potential to experience more conflict with one another because they are likely to have fewer shared experiences, less in common, and more differences of opinion than similar employees (Pfeffer, 1983). Thus, we hypothesize:

Hypothesis 2a (H2a): Holding constant how frequently people interact, people who are more demographically different from their coworkers will experience more conflict when working on tasks than will members who are more similar to their coworkers.

An organization's emphasis on individualistic or collectivistic values will also influence conflict. The increased salience of and members' shared commitment to organizational objectives in collectivistic organizations may operate to create superordinate goals that transcend differences among individuals and, as a result, reduce conflict (e.g., Sherif et al., 1961). Past research found greater cooperative behavior among groups composed of members from nations with collectivistic cultural traditions than among racially homogeneous groups that emphasize individualistic cultural traditions (Cox, Lobel, and McLeod, 1991). Compared with members of individualistic organizations, members working in collectivistic organizations were rated by coworkers as more cooperative (Chatman and Barsade, 1995). Thus, we hypothesize:

Hypothesis $2 b(\mathrm{H} 2 b)$ : Holding constant how frequently members interact, members of organizations that emphasize individualistic values will experience more conflict with coworkers when working on tasks than will members of organizations that emphasize collectivistic values.

While the amount of conflict is important, the constructiveness of such conflict also influences effectiveness (Jehn, 1995). Compared with people who are more demographically different and view each other as out-group members, similar people, or those who are familiar, may feel more comfortable with one another and, as a result, be more likely to engage in constructive debate. Research has shown that work groups with stable membership experience beneficial conflict more often than groups characterized by instability and change among members (Arrow and McGrath, 1993), and groups of friends exhibit more constructive conflict while working on a decision task than groups of strangers (Shah and Jehn, 1993). But if, as we hypothesized above, little conflict exists among similar coworkers, even its positive expression may have little impact on deriving solutions to complex problems. Thus, an organization's emphasis on individualism or collectivism may be relevant to understanding if members, especially those who are demographically different from their coworkers, view the conflict they experi-

754/ASQ, December 1998 
ence as beneficial or detrimental to problem solving. Because collectivistic cultures emphasize common goals, challenges to and disagreements about ideas among members may be viewed as constructive rather than as threatening. Further, research showed that when collectivistic values were emphasized, people were more motivated to combine their different perspectives to reach common goals (e.g., Cox, Lobel, and McLeod, 1991). Conversely, in individualistic cultures, challenges and disagreements, regardless of their source, may be taken more personally and be viewed as competitive (e.g., Axelrod, 1984). We, therefore, predict the following:

Hypothesis 2c $(\mathrm{H} 2 \mathrm{c})$ : Holding constant how frequently people interact, people who are demographically different from their coworkers will view conflict as significantly less beneficial in individualistic cultures relative to collectivistic cultures, while those who are more similar to one another will view conflict as similarly beneficial across the two types of cultures.

\section{Work Outcomes: Creativity and Productivity}

Demographic composition and cultural emphasis may also influence work outcomes, such as creativity and how much work is completed.

Creativity. Research has suggested that heterogeneous groups outperform homogeneous groups on tasks requiring creativity because of the availability of a greater variety of ideas, perspectives, and approaches to solving problems (e.g., Hoffman, 1979; Nemeth, 1992), but holding unique or creative perspectives is not enough to improve solutions. Group members must also be willing to share their novel, controversial, or unique ideas. Studies of information sharing, however, have shown that the probability that a given piece of information will be shared in a group discussion decreases as the number of members who are aware of it decreases (e.g., Stasser and Stewart, 1992). Because creative ideas are typically not commonly held, they are less likely to be shared than are more common or obvious ideas. People can also be reluctant to express novel ideas in organizations (Amabile, 1988), especially to others perceived to be different from them. Information sharing is not constrained by heterogeneity per se, rather, it appears to be based on a lack of trust, as people are reluctant to voice novel or deviant views for fear they will be ridiculed (Nemeth, 1986: 29). Trust can be increased through direct knowledge of others or through substitutes for this knowledge, such as in-group membership that results in depersonalized trust (Brewer, 1981). Social categorization processes such as in-group enhancement and enhanced perceived similarity of actions and attitudes among in-group members can influence individuals' willingness to trust others and, therefore, their willingness to share novel ideas (e.g., Kramer, Brewer, and Hanna, 1996). In-group membership can be based on belonging to the same demographic categories or to the same organization, and for people who are demographically different, trust in other organizational members may arise from the culture within which they operate. To the extent that a collectivistic organizational culture highlights members' common fate and interdependence, they may use organizational membership 
as the basis for categorization, with less regard to their demographic differences.

High levels of creativity may require both demographic heterogeneity, for idea variety, and a basis for common in-group categorization so that heterogeneous individuals have a basis for trust and idea sharing. People who are demographically similar may have the requisite trust in each other, but their ideas may also be so similar that creativity is stunted. Dissimilar people may have the requisite variety of ideas to achieve high levels of creativity but in an individualistic culture they may be inhibited from sharing these ideas because of their lack of trust in each other. In such a culture, sharing information and novel perspectives is risky because of the potential for social ostracism or dilution of individual credit for such ideas or information. Given the lack of a naturally occurring social lubricant (as exists among demographically similar members), organizational culture should have a greater impact on demographically diverse members' production of creative ideas than on those who are similar. Thus, the combination of dissimilar people working together in a collectivistic culture may be the most potent for producing highly creative output. More formally, we predict the following:

Hypothesis $3 a(\mathrm{H} 3 \mathrm{a})$ : Holding constant how frequently people interact, people who are more different from their coworkers will produce significantly more novel solutions when their organizational culture emphasizes collectivism than when it emphasizes individualism, while people working with demographically similar coworkers will vary less in terms of the novelty of their solutions across the two types of cultures.

Productivity. A final consideration is whether organizational composition and culture influence members' productivity in terms of the number of tasks they complete in a given time period. Interacting with others in individualistic cultures will involve little sharing or modification of ideas based on input from others because of a belief in individual accountability. Members of individualistic cultures may not even consider the need to work with others when given a task to complete. In collectivistic cultures, members are more compelled to consider and debate each other's ideas. Further, in organizations composed of demographically similar members, the cultural emphasis will have a less pronounced influence on productivity. Even if similar members in collectivistic cultures are inclined to engage in debate, they have fewer ideas to consider (e.g., Jackson, 1992). When members of an organization are demographically different, cultural emphasis may influence productivity. In individualistic cultures, even when diverse members interact with one another, they may not spend as much time engaging in debate over their ideas, allowing them to complete more tasks in less time. In contrast, diverse members working in collectivistic cultures will be more motivated to consider coworkers' perspectives and will have a wider array of ideas to consider. Because their diverse ideas will be more difficult to integrate, they will take longer to complete their tasks. More formally, we predict the following:

Hypothesis $3 b(\mathrm{H} 3 b)$ : Holding constant how frequently people interact, people who are more demographically different from their coworkers will take longer to make decisions and make fewer deci-

756/ASQ, December 1998 


\section{Being Different}

sions when their organizational culture emphasizes collectivism than when it emphasizes individualism, while people's productivity will vary less between the two cultures when they are working with demographically similar others.

\section{METHOD}

\section{Sample, Procedure, and Design}

Two hundred fifty-eight first-year students enrolled in a twoyear full-time Master's of Business Administration (MBA) program at a major American university participated in an organizational simulation study as part of their required organization behavior course.

The Looking Glass simulation. We modified "Looking Glass Inc." (Lombardo, McCall, and DeVries, 1989), a complex business simulation, to test the hypotheses. This simulation is a flexible, realistic, and engaging way of assessing managerial behavior and has been used in industry for recruiting, training, and promoting managers. Represented in the simulation were 20 managers per organization, ranging from plant managers to vice presidents. Looking Glass Inc. was further divided into three divisions to which a number of tasks pertained: Advanced Products (seven managers), Commercial Glass (six managers), and Industrial Glass (seven managers). Subjects were matched on demographic characteristics (nationality, race, and sex) and randomly assigned to a role in one of 14 simulated organizations. Half the organizations were designated as demographically heterogeneous, while half were designated as demographically homogeneous. But, to assess demographic differences more precisely, we measured each subject's relative differences from others in his or her organization. In contrast, we manipulated the culture of each organization such that half emphasized collectivistic values while half emphasized individualistic values. Both variables are explained more fully below.

Half of the simulated organizations were administered on a Wednesday evening, and the remaining seven were administered on the following Saturday morning. Subjects were asked not to discuss their activities with others who had not yet participated, and debriefing did not occur until the entire study was completed. Subjects had no knowledge of the manipulated conditions or the research hypotheses.

Subjects were given their Looking Glass Inc. packet the night before participating in the simulation. Each packet contained their role assignment, detailed background information about the firm, memos (depending on the role assignment, packets included between 25 and 30 memos on which subjects could take action or make a decision), procedural instructions for the next day, and the culture manipulation check. Subjects were instructed to review the materials for 45 minutes to become familiar with their role, but they were not allowed to make any decisions or to discuss the simulation with anyone before participating.

Upon arriving the next evening (or morning), subjects were directed to their organization, seated at a desk with their name and job title on it, and provided with various office supplies. They were also supplied with an organization chart that specified the name, job title, and division of each individual in their organization. The first message delivered was a memo from the "president" of Looking Glass Inc. In all

757/ASQ, December 1998 
conditions, the organization chart specified that a subject androgynously named Pat Stephenson was playing the role of the Looking Glass Inc. president. This was a fictitious person, however, as we intentionally did not assign any participants to the role of president. The memo specified that the president would hold a "state-of-the-firm" address for all employees in 3.5 hours and that they should focus their efforts on three particular issues in the meantime. We designed these "salient tasks" to be complex and have broad organizational implications. They included (1) a performance appraisal task that required subjects to weight the importance of various attributes that should be used on organizational performance appraisals (e.g., planning and organization, results orientation); (2) an asbestos cost allocation task requiring subjects to determine ways of paying for asbestos removal in the Looking Glass Inc. plants; and, (3) a total quality management (TOM) task, requiring that subjects develop suggestions for improving procedures or products at Looking Glass Inc.

Ten minutes before the state-of-the-firm address was to convene and forty minutes before the simulation ended, a final "faxed" memo marked "urgent and confidential" was distributed to each participant from the president. In this memo the president explained that he/she was in an emergency meeting with the board of directors and that each LG Inc. division (APD, CGD, and IGD) would be required to downsize by one executive-level position (vice president to plant manager) immediately to maintain LG Inc.'s viability. Participants were asked to give the messenger a memo that would be "faxed" to the president laying out a decision-making strategy to fulfill this executive reduction requirement. The memo also canceled the state-of-the-firm address and suggested that participants instead devote the 30 minutes to addressing the downsizing requirement. We focused subjects' attention on these four varied tasks (the three mentioned above plus the downsizing task) to increase their ability to recall specific aspects of their approach to these tasks, such as how many people they met with and how much conflict they experienced, to increase the reliability of their post-simulation survey responses. These tasks were the only four that were common to all subjects in all roles.

Subjects spent four hours dealing with issues from their inbasket in any way that they chose (writing memos to others, having conversations with others, working on their own, etc.). A messenger service was available if subjects wanted to "mail" memos to other members of their organization. Mail was collected and delivered every 15 minutes during the simulation by research assistants, who were instructed not to discuss any substantive issues with participants.

Subjects' behavior in the simulation was tracked through the memos that they sent and received and through their responses to the post-simulation survey. Subjects were given carbon paper to send copies to multiple recipients if they wished. They were instructed to write down all decisions that were made or discussed, and all written materials were collected at the end of the simulation. Subjects completed an extensive survey at the end of the simulation, requesting information about their experience during the simulation. Fi-

758/ASQ, December 1998 


\section{Being Different}

nally, subjects were excused, and debriefing occurred during the class period following the final administration of the simulation.

\section{Independent Variables}

Relational demography. Subjects' nationality, race, and sex were collected from university records. We manipulated organizational composition at the organization level because we were interested in testing the hypotheses in situations in which demographic characteristics were either similar for all members or varied for all members. Our hypotheses were not relevant to the situation in which a single member of a demographic group is working with others who are similar to one another but different from that person, for example, one woman in an organization of 19 men. Seven of the 14 organizations contained homogeneous subjects who were the same national origin, race, and sex (only with white U.S.born males or females). The other seven were diverse in that members represented different nationalities, races, and sexes. Two organizations were specified as all-female organizations, one with white, U.S. citizens, the other with diversity on these two attributes. We used the two all-female organizations to explore the differences between numeric distinctiveness, or how diverse a group is in terms of the numeric composition of demographic categories, and historical distinctiveness, or how typical it is for people from a particular social category to be in the majority or minority in this context (e.g., Kanter, 1991). Because people still varied slightly in terms of their similarity to or differences from their coworkers on the three demographic attributes within each condition, we calculated relational difference scores for each individual and used this score in all hypothesis tests. Measuring relational demography, rather than relying on dichotomous organizational composition conditions, allows for a more fine-grained analysis of demographic composition.

Individual-level relational demography scores represent the difference between a subject and all other subjects in his or her organization on nationality, race, and sex. Following Tsui and O'Reilly (1989), relational demography was measured using the following equation: $\left[1 / n \Sigma\left(x_{i}-x_{j}\right)^{2}\right]^{1 / 2}$, where: $x_{i}=$ the focal individual's score on the dimension (e.g., $0=$ male, $1=$ female); $x_{j}=$ each other member's score on that dimension; and $n=$ the number of subjects in the organization. Differences in nationality, race, and sex are each represented by a score ranging from 0 to 1.0 , with higher scores on each measure indicating greater differences between the person and other organization members on this dimension. We computed the overall relational demography score as the average of the relational demography scores across these three dimensions. To ensure that our assignment procedure produced significant differences between homogenous and heterogeneous organizations, we assessed subjects' average relational demography score in homogeneous organizations $(\bar{x}=.07$, s.d. $=.09)$ and in heterogeneous organizations $(\bar{x}=.60$, s.d. $=.17)$. An ANOVA showed that these means were significantly different $[F(1,253)=914.44 ; p<.0001]$. Thus, comparing the relational demography scores of those in homogeneous and heterogeneous organizations, in effect, assessed differences be- 
tween people who were working in organizations in which their coworkers were relatively similar to themselves and in which their coworkers were relatively different from them.

Collectivistic versus individualistic culture. We developed three ways to manipulate the culture at Looking Glass Inc. First, in addition to providing various administrative information (e.g., organization chart, list of employees, calendar), we added the following paragraph to the company description appearing on the first page of each subject's Looking Glass materials:

The president and founder of Looking Glass Inc., M. L. Smith, is still the driving force of Looking Glass Inc.'s corporate culture. He and the founding senior managers are proud of LG Inc.'s reputation in the industry as an individualistic [or team] organization. At LG Inc. individual effort and initiative [or cooperation and teamwork] are highly valued and rewarded, and competition [or cooperation] among individuals and departments is considered to be the best road toward innovation and success. Both employees and outsiders categorize LG Inc. as having a very individualistic [or collectivistic] culture.

The second culture manipulation consisted of information about subjects' compensation and bonus. In the individualistic culture condition, subjects were informed that their bonus was "based on individual achievement and contribution to Looking Glass Inc.'s performance," and in the collectivistic condition it was "based on teamwork and the team's contribution to Looking Glass Inc.'s performance." Third, subjects were invited to an "Individuals [or Teams] are the Reason for our Success" awards celebration. Award winners were listed on the invitation either with individual names (individualistic culture condition) or as entire work teams (collectivistic culture condition). These two manipulations were interspersed among the middle and end pages, respectively, of the many pages of simulation materials.

Each manipulation was designed to operationalize our conceptual definition of individualism-collectivism and the salience of organizational membership. Thus, the organization was portrayed as valuing and rewarding individual achievement, effort, and initiative in the individualistic condition and cooperation, shared benefits, and teamwork in the collectivistic condition. The bonus and award ceremony manipulations, in particular, were intended to simulate differences in the salience of organizational membership. In the individualistic condition people could be successful (get larger bonuses and awards) based solely on their own accomplishments, regardless of their relationships with others. This should have increased their focus on what differentiated them from others. In contrast, in the collectivistic condition, success was contingent on coordinated performance among organizational members, increasing the salience of shared objectives and commonalties among members. Finally, these manipulations did not provide any instructions for how participants should approach the tasks (e.g., interacting with others via written correspondence or working alone). Rather, the manipulations merely conveyed information about the values, beliefs, and rewards associated with the organization, matching our conceptualization of culture.

To test the effectiveness of our culture manipulation, subjects were asked to complete the "Organizational Culture

760/ASQ, December 1998 


\section{Being Different}

Diagnosis Survey" (developed for this study) the night before the simulation, after they reviewed the materials but before they participated in the simulation. This survey asked respondents to rate 13 dimensions of Looking Glass Inc.'s organizational culture, four of which were relevant to individualism-collectivism, on a 7-point Likert-type scale (from $1=$ "extremely uncharacteristic" to $7=$ "extremely characteristic"). As expected, subjects in the two culture conditions differed in their perceptions of how individualistic [individualistic culture $\bar{x}=5.74$, collectivistic culture $\bar{x}=3.52$; $F(1,251)=153.63, p<.001]$ and collectivistic the culture was [individualistic culture $\bar{x}=3.69$, collectivistic culture $\bar{x}=5.14$; $F(1,247)=79.08, p<.001$ ], and how competitive [individualistic culture $\bar{x}=5.67$, collectivistic culture $\bar{x}=4.36$; $F(1,252)=74.00, p<.001]$ and team-oriented the culture was [individualistic culture $\bar{x}=3.43$, collectivistic culture $\bar{X}=5.72 ; F(1,252)=185.43, p<.001]$.

To ensure that the culture manipulation persisted until the end of the simulation, we re-administered the Organizational Culture Diagnosis Survey after the simulation concluded. We again found significant differences between the subjects' culture ratings in the two culture conditions in the expected directions, mirroring the results from the pre-simulation manipulation check. Ratings were significantly different for the extent to which the organization was characterized as individualistic [individualistic culture $\bar{x}=5.37$, collectivistic culture $\bar{x}=3.50 ; F(1,236)=98.37, p<.001$ ], collectivistic [individualistic culture $\bar{x}=4.05$, collectivistic culture $\bar{x}=5.26$; $F(1,235)=47.70, p<.001$ ], competitive [individualistic culture $\bar{x}=4.93$, collectivistic culture $\bar{x}=3.85 ; F(1,236)=37.14$, $p<.001$ ], and team-oriented [individualistic culture $\bar{x}=3.78$, collectivistic culture $\bar{x}=5.56 ; F(1,236)=86.79, p<.001]$. Only the extent to which the organization was viewed as competitive changed over the course of the simulation, with subjects rating their culture as significantly more competitive before the simulation $(\bar{x}=4.90)$ than after the simulation $(\bar{x}=4.30)[t(230)=6.12, p<.001]$. This shift occurred in both the individualistic and collectivistic culture conditions.

\section{Dependent Variables}

Salience of social categories. On the post-simulation survey, subjects were asked to report the extent to which various social categories were salient to them during the simulation. They responded to the question: "During the simulation, to what extent were your decisions and actions influenced by your membership in the following groups?" Subjects rated six items on a scale from 1 ("I never thought about my membership in this group.") to 7 ("I frequently thought about my membership in this group."). Two factors emerged from a factor analysis, using varimax rotation, of these items. Three items loaded on a factor representing demographic attributes: sex, race, and nationality (eigenvalue $=2.57$ ), accounting for 43 percent of the variance. Three items loaded on a second factor representing organizational attributes: "your entire Looking Glass organization," "your job level within Looking Glass," and "your division within Looking Glass" (eigenvalue $=1.34$ ), accounting for 22 percent of the variance. We developed two scales based on these results (demographic attributes scale: $\bar{x}=2.14$,

761/ASQ, December 1998 
s.d. $=1.73$; organizational attributes scale: $\bar{x}=4.33$,

s.d. $=1.13$ ) and used the scales in subsequent analyses.

Interaction with coworkers. The first of two measures of coworker interaction consisted of a count of all the memos each respondent sent to other people in his or her organization during the simulation on all tasks (not just the four salient tasks) $(\bar{x}=9.48$; s.d. $=6.49$ ). The second measure consisted of respondents' reports on the post-simulation survey of the number of people they met with during the simulation while working on each of the four salient tasks (the tasks they were assigned by the president: asbestos, downsizing, performance appraisal, and TQM). Subjects' responses were averaged across the four questions, and this average score was used in subsequent analyses (overall mean for number of people met with $=3.33$; s.d. $=1.93$ ).

Conflict. Conflict was assessed by responses to the question, "If you worked with others on this task, how much conflict existed among those who were involved in completing the task?" Respondents answered this question four separate times in the post-simulation survey, once for each of the four salient tasks. They used a 7-point Likert-type response scale on which 1 represented "no conflict" and 7 represented "extreme conflict." For each individual, the responses were summed and divided by the number of tasks on which they reported interacting with coworkers. This mean score was used to represent conflict $(\bar{x}=2.50$; s.d. = 1.18). If subjects' rating on the conflict question for a task was greater than 1 , they also responded to the question, "To what extent was the conflict beneficial or detrimental to accomplishing the task?" ( 1 = detrimental; 7 = beneficial). These scores were also averaged across the tasks addressed by subjects ( $\bar{x}=4.62$; s.d. $=1.25)$.

Performance: Idea quality and productivity. The TOM task was designed to test our creativity hypothesis. Idea creativity was assessed through self-report and expert ratings. The self-reported measure of creativity consisted of subjects' response to the question, "How creative are your quality applications?" using a Likert scale ( 1 = "not at all creative" to $7=$ "extremely creative"). The mean for this scale was 3.95 (s.d. = 1.55). Three independent judges who had worked in quality management in both the private and public sectors also rated every TQM suggestion by responding to the same question used for the self-report response described above (except that the question was phrased appropriately for assessing single suggestions). Each suggestion was separated and randomly assigned so that the judges were unaware of which subjects wrote which suggestions and to avoid order biases. The reliability among the judges across suggestions was .87 (Cronbach's alpha). We then averaged the three ratings for each suggestion across judges and summed these mean ratings for all the ideas each subject produced. This created a variable that incorporated both the number of ideas and the creativity of those ideas. This approach was intended to match closely the way that individuals would rate their own creativity. We assumed that a person would focus on the total creativity of all his or her ideas, rather than on the average creativity of these ideas, when rating his or her own creativity. Thus, a subject suggesting two extremely

762/ASO, December 1998 


\section{Being Different}

creative ideas (each with a mean expert rating of 5 ) received a creativity score of 10 , while a subject with three average ideas (each with an expert rating of 3 ) received a score of 9 . A mean rating could not have captured both the level of creativity and the number of ideas a person suggested. The mean for the summed total creative output scale was 8.59 (s.d. = 5.93).

Productivity was assessed in three ways: (1) as a count of how many of the four salient tasks subjects had completed, defined as reaching a decision; 72 percent of subjects completed the performance appraisal task, 43 percent completed the asbestos cost allocation task, 42 percent completed the total quality management task, and 40 percent completed the downsizing task; (2) the average number of minutes spent on each of the four tasks reported by each subject $(\bar{x}=16.66$ minutes per task; s.d. $=9.99)$; and $(3)$ the percentage of total tasks each subject addressed, calculated as the number of tasks on which subjects took some action (e.g., taking notes, requesting additional information, making a decision), divided by the total number of tasks included in his or her specific Looking Glass role $(\bar{x}=23$ percent of total tasks; s.d. = 11 percent of total tasks).

\section{Control Variables}

We included a variety of control variables in each analysis to rule out alternative explanations for effects. Dichotomous dummy variables for nationality $(0=$ U.S., $1=$ non-U.S.), race ( $0=$ white, $1=$ non-white $)$, and sex ( $0=$ male, $1=$ female $)$ were included to control for the possibility that demographic patterns influenced one nationality, race, or sex more than others. These three variables were entered on the first step of each hierarchical regression equation.

We included two control variables that pertained specifically to the Looking Glass simulation. The first was a division dummy variable to rule out any differences in outcomes attributable to the slight differences in tasks assigned to each division (the four assigned by the president were identical regardless of division). We also created a dummy variable to control for a participant's job level (vice president, director, or plant manager), as greater formal authority could influence one's work processes and outcomes.

We controlled for three variables pertaining to the simulation procedures and to the minor differences in distributions of subjects in our sample. First, we created a dummy variable for date of participation $(0=$ Wednesday evening; 1 = Saturday morning) to rule out effects for the day of the week individuals participated. We also created a dummy variable for the fourteenth group because it contained only eleven instead of twenty members (all other groups only varied in size by one or two members). Finally, we created a dummy variable that identified the two homogenous all-female groups. Because an all-female business organization is unusual in American businesses, we wanted to rule out variations in demand effects across the simulated organizations.

Finally, we controlled for the number of prior friends subjects had in their simulated organization. Randomly assigning subjects to organizations should have eliminated an alterna-

763/ASQ, December 1998 
tive explanation for our results based on prior friendship. To be sure, however, we measured the number of friends each subject had in his or her assigned organization. The night before the simulation, subjects were asked to indicate from a list of all first-year MBA students all those who were personal friends and rate each friend on a scale of 1-5 ( $1=$ casual friend; $3=$ moderately close friend; $5=$ very close friend). For each subject we created a dichotomous variable for each other organizational position $(0=$ not a friend; $1=$ friend to any extent). We then summed these dichotomous variables for each participant. Thus, a score of 5 on this friendship variable, for example, indicates that prior to the simulation the subject had listed five members of his or her organization as friends. These six control variables were entered on the second step of the hierarchical regression equations. Two additional control variables for the amount of interaction among participants (number of memos sent and number of people met with) were entered for hypotheses $2 a-3 b$ following the nine standard control variables listed above.

\section{Analysis}

We used hierarchical regressions and slope analyses to test each hypothesis, entering the control variables on the first and second steps as specified above. The third block consisted of the two independent variables (relational demography and organizational culture). The final block contained the term for the interaction between relational demography and culture. We tested predictions for interactions between relational demography and culture on the dependent variables (hypotheses 1c, 2c, 3a, 3b), if the interaction coefficient was significant, using a slope analysis appropriate for one continuous variable (relational demography) and one dichotomous variable (culture). We conducted slope analyses rather than an analysis of means because we did not want to discard information by dichotomizing the continuous relational demography measure (Cohen and Cohen, 1983). We used the following equation: $y=a+b_{1} x_{1}+b_{2} x_{2}+b_{3} x_{1} x_{2}+e$, where $y=$ the dependent variable; $a=$ the constant; $b_{1}=$ the unstandardized coefficient for culture; $x_{1}=$ a dummy code for culture; $b_{2}=$ the unstandardized coefficient for relational demography; $x_{2}=$ the value of the relational demography variable; $b_{3}=$ the unstandardized coefficient for the interaction term; and $e=$ the error term (Jaccard, Turrisi, and Wan, 1990). Using this equation twice for each dependent variable, we substituted the dummy code for organizational culture $10=$ individualistic in the first equation; $1=$ collectivistic in the second equation) wherever $x_{1}$ appeared and solved for $x_{2}$, resulting in a separate equation for each type of organizational culture. The slopes that appear in these two equations are considered significantly different when the coefficient for the interaction term is significant in the original regression equation. The difference between the slopes equals the unstandardized coefficient for the interaction term. We compared the direction and magnitude of the slopes to determine the form of the interaction. Sample relational demography scores (with heterogeneity increasing from 0 to 1) can be substituted for $x_{2}$ in the reduced equation for each culture condition to demonstrate how the dependent variable

764/ASQ, December 1998 


\section{Being Different}

changes in direction and magnitude as heterogeneity increases.

\section{RESULTS \\ Propositions}

Our initial propositions propose relationships between social categorization and both demographic diversity and cultural emphasis. To examine these relationships, we conducted a multiple analysis of variance (MANOVA) in which the scale of demographic categories and the scale of organizational categories were dependent variables, and organizational culture (a dichotomous measure) and relational demography (a continuous measure) were independent variables. We proposed that being different would affect the salience of demographic categories, but we found no significant effect for subjects' relational demography on the extent to which demographic categories were salient [univariate $F(1,241)=$ 1.16, n.s.]. This effect became significant [multivariate $F(2,240)=2.44, p<.10$; univariate $F(1,241)=4.90, p<.03]$, however, with a positive relationship between degree of demographic differences and salience of demographic categories, when we removed sex from the demographic attributes scale (alpha of scale with race and citizenship $=.93$ ). This difference may have to do with the atypicality of all-female work organizations. Historical distinctiveness may contrast with the numerical distinctiveness that was operating in conditions in which all demographic attributes were varied. In the two all-female organizations, participants rated the salience of sex as a demographic category significantly higher $(\bar{x}=3.21)$ than did participants in all other organizations $[\bar{x}=2.36 ; F(1,249)=5.43, p<.05]$. Thus, even though no diversity existed on sex in these organizations, it may have been highly salient because of how unusual it was, especially for business school students, to be in an all-female organization. We address this issue further through additional analyses reported below.

The effects of culture on the salience of organizational attributes as social categories were clearer. The MANOVA revealed that subjects in collectivistic cultures viewed membership in organizational categories as significantly more salient $(\bar{x}=4.50)$ than did subjects in individualistic cultures $[\bar{x}=4.14$; multivariate $F(2,240)=3.90, p<.05$; univariate $F(1,241)=7.77, p<.01]$. Culture did not significantly affect the salience of demographic categories, nor did relational demography significantly affect the salience of organizational attributes. Finally, we found that, as proposed, the salience of demographic categories was inversely related to the salience of organizational membership $(r=-.13, p<.05)$, supporting the existence of functional antagonism between these two categories.

\section{Hypothesis Tests}

Table 1 reports the means, standard deviations, and zeroorder correlations among the control, independent, and dependent variables.

Hypothesis 1: Interaction among coworkers. H1a predicted that members of heterogeneous organizations would 
Means, Standard Deviations, and Correlations among Variables

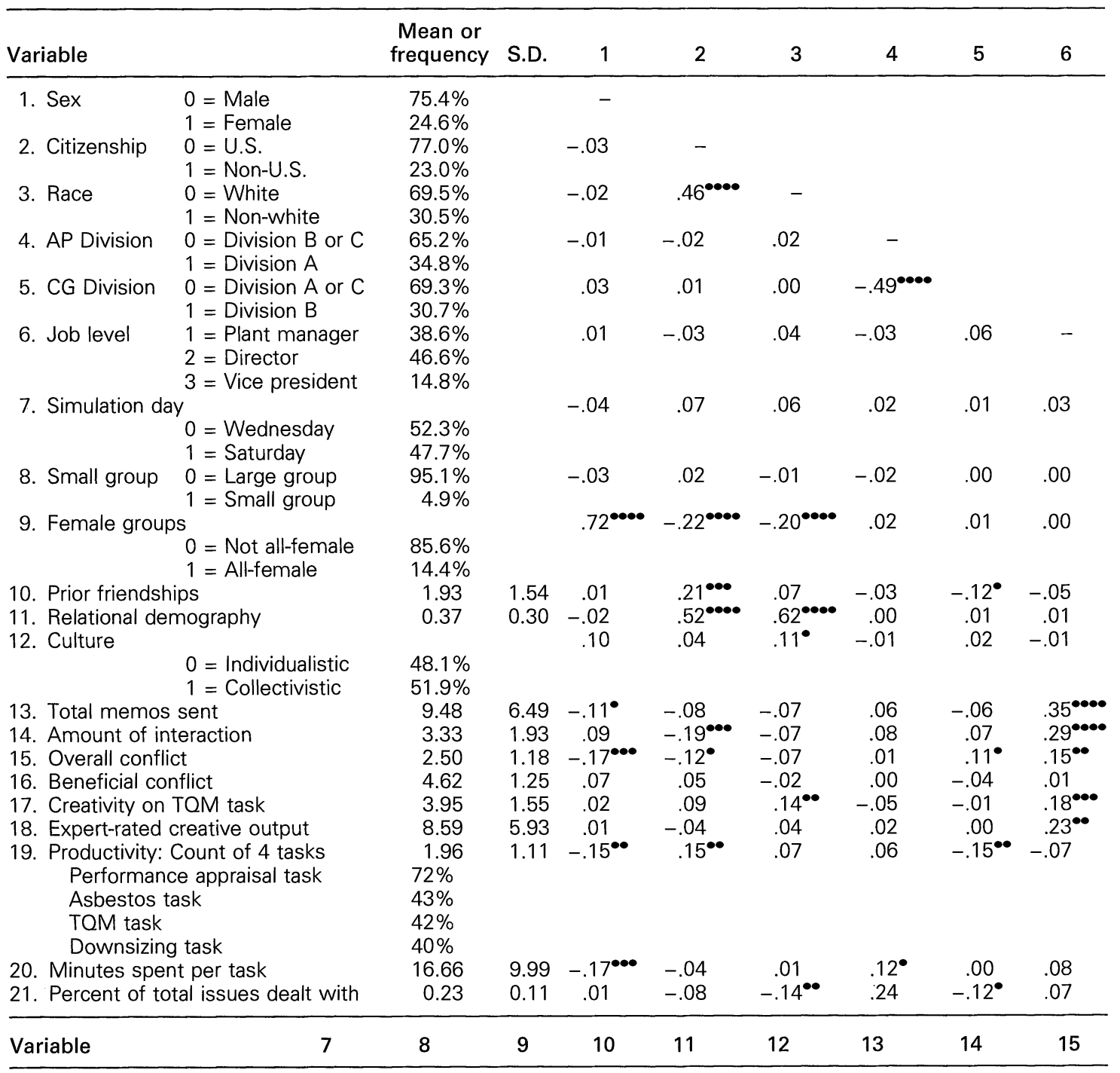

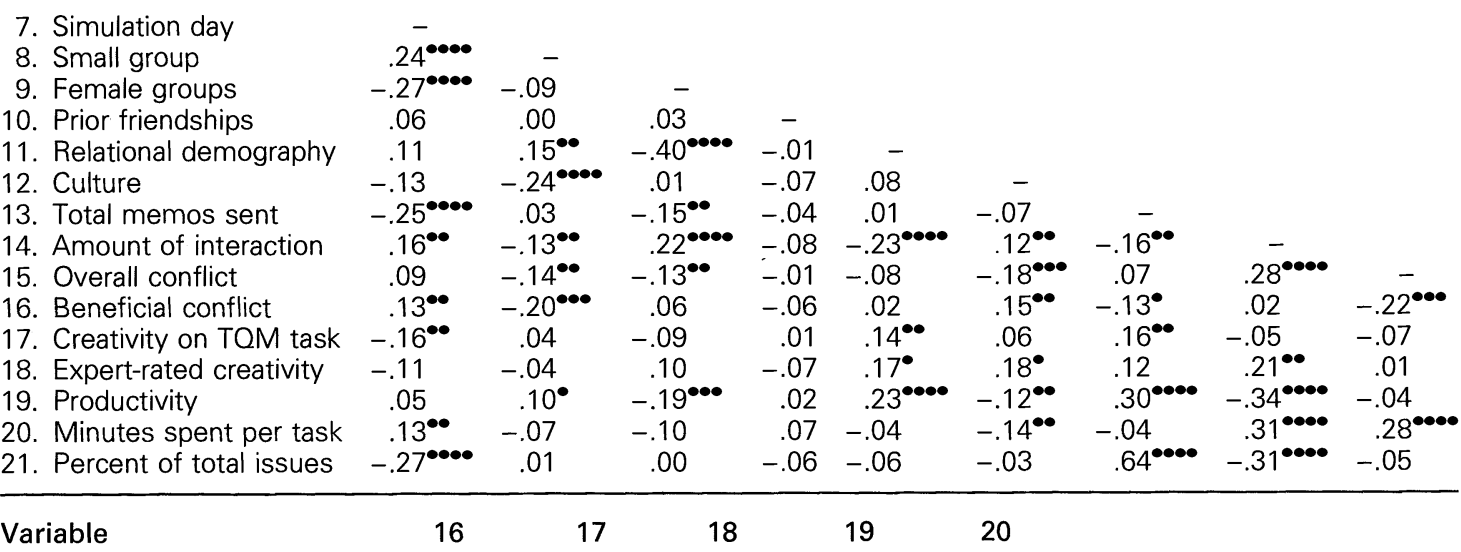

16. Beneficial conflict

17. Creativity on TQM task

18. Expert-rated creativity

19. Productivity

20. Minutes spent per task

$-$

$\begin{array}{ll}- & \\ .15^{\bullet \bullet} & - \\ .06 & .26^{\bullet \bullet} \\ .13^{\bullet \bullet} & .10 \\ -.01 & .01 \\ -.09 & .09\end{array}$

-.01
.15

$\begin{array}{llll}.09 & .01 & .02 & - \\ .00 \cdots & -.07\end{array}$

$\bullet p<.10 ; \stackrel{\bullet \bullet}{ } p<.05 ;{ }^{\bullet \bullet} p<.01 ;{ }^{\bullet \bullet \bullet} p<.001$. 


\section{Hierarchical Regression Equations Predicting Work Processes*}

\begin{tabular}{|c|c|c|c|c|}
\hline \multirow[b]{2}{*}{ Variable } & \multicolumn{2}{|c|}{ Social Interaction } & \multicolumn{2}{|c|}{ Conflict } \\
\hline & $\begin{array}{c}\text { Total memos } \\
\text { sent (directly } \\
\text { and } \mathrm{cc}^{\prime} \mathrm{d} \text { ) } \\
1\end{array}$ & $\begin{array}{c}\text { Amount of } \\
\text { interaction } \\
\text { with coworkers } \\
2\end{array}$ & $\begin{array}{c}\text { Overall } \\
\text { conflict } \\
\text { with others } \\
3\end{array}$ & $\begin{array}{c}\text { Benefit } \\
\text { of conflict } \\
\text { with others } \\
4\end{array}$ \\
\hline Sex & $-.11^{\bullet}$ & .08 & $-.17^{\bullet \bullet \bullet}$ & .08 \\
\hline Citizenship & -.06 & $-.20^{\bullet \bullet \bullet}$ & -.11 & .08 \\
\hline Race & -.05 & .03 & -.02 & -.06 \\
\hline Contribution to $R^{2}$ & .02 & .04 & .04 & .01 \\
\hline AP Division & .05 & $.13^{\bullet \bullet}$ & .07 & -.04 \\
\hline CG Division & -.05 & $.12^{\bullet}$ & $.14^{\bullet \bullet}$ & -.07 \\
\hline Job level & $.36^{\bullet \bullet \bullet \bullet}$ & $.27^{\bullet \bullet \bullet \bullet ~}$ & $.14^{\bullet \bullet}$ & .02 \\
\hline Simulation day & $-.27^{\bullet \bullet \bullet \bullet ~}$ & $.19^{\bullet \bullet \bullet}$ & $.14^{\bullet \bullet}$ & $.20^{\bullet \bullet \bullet}$ \\
\hline Small group & .07 & $-.15^{\bullet \bullet}$ & $-.18^{\bullet \bullet \bullet}$ & $-.25^{\bullet \bullet \bullet \bullet}$ \\
\hline Female groups & $-.18^{\bullet \bullet}$ & $.25^{\bullet \bullet \bullet}$ & -.13 & -.04 \\
\hline Prior friendships & -.01 & .03 & -.03 & -.08 \\
\hline Contribution to $R^{2}$ & .22 & .18 & .09 & .09 \\
\hline Amount of interaction & & & $.26^{\bullet \bullet \bullet \bullet}$ & -.06 \\
\hline Total memos sent & & & .10 & -.11 \\
\hline Contribution to $R^{2}$ & & & .05 & .01 \\
\hline Amount of overall conflict (CON) & & & & $-.29^{\bullet \bullet \bullet \bullet}$ \\
\hline Contribution to $R^{2}$ & & & & .06 \\
\hline Relational demography (RD) & .08 & $-.19^{\bullet \bullet}$ & -.01 & .07 \\
\hline Organizational culture (OC) & -.07 & $.14^{\circ \bullet}$ & $-.24^{\bullet \bullet \bullet \bullet}$ & .06 \\
\hline Contribution to $R^{2}$ & .00 & .03 & .05 & .01 \\
\hline $\mathrm{RD} \times \mathrm{OC}$ & $.39^{\bullet \bullet \bullet}$ & $-.34^{\bullet \bullet \bullet}$ & .11 & $.38^{\bullet \bullet}$ \\
\hline Contribution to $R^{2}$ & .04 & .02 & .00 & .02 \\
\hline$R^{2}$ & .28 & .27 & .23 & .20 \\
\hline Adjusted $R^{2}$ & .23 & .23 & .18 & .14 \\
\hline Overall F-ratio & $6.86^{\bullet \bullet \bullet \bullet}$ & $6.88^{\bullet \bullet \bullet \bullet ~}$ & $4.56^{\bullet \bullet \bullet \bullet ~}$ & $3.05^{\bullet \bullet \bullet \bullet ~}$ \\
\hline D.F. & 13,235 & 13,239 & 15,230 & 16,190 \\
\hline
\end{tabular}

$\bullet p<.10 ;{ }^{\bullet \bullet} p<.05 ;{ }^{\bullet \bullet \bullet} p<.01 ;{ }^{\bullet \bullet \bullet} p<.001$.

* Entries represent standardized coefficients and are reported in the order entered.

interact with each other less frequently than would members of homogeneous organizations. The two indicators of interaction were moderately inversely correlated $(r=-.16$, $p<.05$ ), suggesting that meeting with people partially substituted for sending memos. Table 2 (models 1 and 2) shows partial support for $\mathrm{H} 1 \mathrm{a}$. While relational demography did not influence the number of memos sent to others in the organization, members who were more demographically different from coworkers reported meeting with significantly fewer people compared with members who were more like their coworkers. Hypothesis $1 \mathrm{~b}$, which predicted that members in collectivistic organizations would report interacting more frequently with each other than would members of individualistic cultures, was partially supported. The number of memos sent was not influenced by cultural values, but those in collectivistic cultures met with significantly more coworkers.

$\mathrm{H} 1 \mathrm{c}$ predicted that group composition and cultural values would interact such that demographically different people would be more influenced by the cultural emphasis on individualism or collectivism in their contact with others than would similar members. Table 2 (models 1 and 2) shows that the interaction between organizational culture and relational demography was significant for both the number of memos sent and the number of coworkers with whom sub-

767/ASQ, December 1998 
jects met. We used the slope analysis to examine the form of these interactions: for individualistic culture, number of memos sent $(\mathrm{NOMS})=7.673+-3.808(0)+-3.647\left(\mathrm{x}_{2}\right)+$ $8.316(0)\left(x_{2}\right)+e$, which reduces to NOMS $=7.673+$ $-3.647\left(x_{2}\right)+$ e. For the slope of NOMS on relational demography for collectivistic culture, NOMS $=7.673+-3.808(1)+$ $-3.647\left(\mathrm{x}_{2}\right)+8.316(1)\left(\mathrm{x}_{2}\right)+\mathrm{e}$, which reduces to NOMS $=$ $3.865+4.669\left(x_{2}\right)+$ e. For illustrative purposes, we can in: sert the two mean values of relational demography in the homogeneous $(\bar{x}=.07)$ and heterogeneous $(\bar{x}=.60)$ organizations for each equation: $[7.673+-3.647(.07)]=7.42$; $[3.865+4.669(.07)]=4.19$ versus $[7.673+-3.647(.60)]=$ $5.48 ;[3.865+4.669(.60)]=6.67$. This shows that subjects who are more similar to others sent more memos in the individualistic condition than in the collectivistic condition, while subjects who were dissimilar to others sent more memos in the collectivistic condition than in the individualistic condition. This pattern offers partial support for $\mathrm{H} 1 \mathrm{c}$, as interaction among dissimilar people was higher in collectivistic than individualistic cultures.

For the number of coworkers met with, the reduced slope equation for individualistic cultures was $y=.990+.152\left(x_{2}\right)+e$; and for collectivistic cultures it was $y=2.271+-1.965\left(x_{2}\right)+e$. This reveals that subjects who were more similar met with more coworkers in the collectivistic condition than in the individualistic condition, while there was no difference in the number of coworkers dissimilar others met with across the two culture conditions. Culture had more of an impact as a person's demographic similarity to his or her coworkers increased, contrary to our prediction in $\mathrm{H} 1 \mathrm{c}$. Unlike the result for number of memos sent, however, as similarity increased, the number of people met with was significantly higher in collectivistic than individualistic cultures. Thus, culture moderated the effect of relational demography on social interaction, as predicted. These results suggest that interaction was relatively high among similar people, but the type of interaction differed by cultural condition. For similar people, individualistic cultures caused high memo sending but low face-to-face interaction, while collectivistic cultures caused low memo sending but high face-to-face interaction. For dissimilar people, interaction also depended on the cultural condition, but the pattern was different than for similar people. For dissimilar people, individualistic cultures caused both memo sending and faceto-face interaction to be low, while in collectivistic cultures, face-to-face interaction was low but memo sending was relatively high. Taken together, either memo sending or face-toface interaction occurred with relatively high frequency in all conditions except among dissimilar people in individualistic cultures.

Hypothesis 2: Conflict. We predicted that members who were more different from their coworkers $(\mathrm{H} 2 \mathrm{a})$ and members of individualistic cultures $(\mathrm{H} 2 \mathrm{~b})$ would experience more conflict than would those who were more similar to coworkers and working in collectivistic cultures, respectively. Table 2 (model 3) shows the regression results of tests of these predictions. H2a was not supported, but, as predicted in

768/ASQ, December 1998 
$\mathrm{H} 2 \mathrm{~b}$, more conflict occurred when subjects worked in individualistic cultures than in collectivistic cultures. $\mathrm{H} 2 \mathrm{c}$ predicted that as people's demographic dissimilarity to others increased, assessments of the benefits of conflict would be more influenced by whether the culture emphasized individualistic or collectivistic values. Both the amount of interaction (memos sent and face-to-face) and conflict were controlled when predicting how beneficial the conflict was, since the amount of conflict could be correlated with the evaluation of its benefit. Table 2 (model 4) shows that the interaction between relational demography and culture significantly affected the extent to which conflict was viewed as beneficial. The slope analysis for this interaction revealed that the type of culture had a stronger impact on people who were different from coworkers than it did on people who were similar, as predicted. In the individualistic culture condition, the reduced equation was: beneficial conflict $=5.347+-.654\left(\mathrm{x}_{2}\right)+$ $e$, while in the collectivistic culture condition, the reduced equation was: beneficial conflict $=4.946+.887\left(x_{2}\right)+e$. Thus, as dissimilarity increased, those in collectivistic cultures viewed conflict as more beneficial than did those in individualistic cultures.

Hypothesis 3: Performance. Table 3 shows the results of the test of $\mathrm{H} 3 \mathrm{a}$, predicting subjects' successful development of novel solutions, one of the most widely purported benefits of diversity (models 1 and 2). The interaction between organizational culture and relational demography significantly affected subjects' self-reported creativity on the TQM task, as predicted. The slope analysis equations reduced to $y=3.882+-0.441\left(x_{2}\right)+e$ for individualistic cultures and to $y=3.198+1.595\left(x_{2}\right)+$ e for collectivistic cultures. As dissimilarity increased, subjects' creativity decreased in individualistic cultures but increased in collectivistic cultures, such that the highest rated creativity occurred among dissimilar people in collectivistic cultures. The interaction predicting expert judges' ratings of subjects' creativity was not significant (see table 3, model 2), but we found a strong main effect for relational demography, suggesting that people who were more different came up with more creative ideas for the TQM effort at Looking Glass Inc. We also found a marginally significant main effect for culture, indicating that people in collectivistic cultures had slightly more creative ideas than did those in individualistic cultures. Thus, H3a received support for subjects' self-perceptions of creativity, and, while we did not find that culture moderated relational demography for experts' ratings of creativity, the significant main effects indicate that the highest total creative output was achieved by dissimilar people in collectivistic cultures.

$\mathrm{H} 3 \mathrm{~b}$ predicted that culture would have a greater impact on productivity among subjects who were more different than their coworkers than among those who were more similar to their coworkers. These results are shown in table 3 (models 3,4 , and 5). In model 3 we found, unexpectedly, that those who were more different from their coworkers finished more of the four tasks. The interaction term was also significant, and we conducted the slope analysis. The reduced equations were, for individualistic culture, $y=2.174+$ $0.148\left(x_{2}\right)+e$, and for collectivistic culture, $y=1.688+$

769/ASQ, December 1998 


\begin{tabular}{|c|c|c|c|c|c|}
\hline \multicolumn{6}{|c|}{ Hierarchical Regression Equations Predicting Work Outcomes* } \\
\hline \multirow[b]{2}{*}{ Variable } & \multicolumn{2}{|c|}{ Creativity } & \multicolumn{3}{|c|}{ Productivity } \\
\hline & $\begin{array}{c}\text { Creativity } \\
\text { on TQM } \\
\text { task } \\
1\end{array}$ & $\begin{array}{c}\text { Expert-rated } \\
\text { creative } \\
\text { output } \\
2\end{array}$ & $\begin{array}{l}\text { Count } \\
\text { of four } \\
\text { tasks } \\
3\end{array}$ & $\begin{array}{l}\text { Minutes } \\
\text { spent per } \\
\text { task } \\
4\end{array}$ & $\begin{array}{l}\text { Percent of } \\
\text { total issues } \\
\text { dealt with } \\
5\end{array}$ \\
\hline Sex & .09 & .01 & $-.15^{\bullet \bullet}$ & $-.17^{\bullet \bullet \bullet}$ & .00 \\
\hline Citizenship & .08 & -.07 & $.14^{\bullet}$ & -.06 & -.02 \\
\hline Race & $.15^{\bullet \bullet}$ & .07 & .01 & .03 & $-.13^{\bullet}$ \\
\hline Contribution to $R^{2}$ & .05 & .01 & .04 & .03 & .02 \\
\hline AP Division & .03 & .01 & -.02 & $.13^{\bullet}$ & $.25^{\bullet \bullet \bullet \bullet ~}$ \\
\hline CG Division & -.04 & -.01 & $-.16^{\bullet \bullet}$ & .06 & -.01 \\
\hline Job level & $.10^{\bullet}$ & $.23^{\bullet \bullet}$ & -.04 & .09 & .10 \\
\hline Simulation day & $-.20^{\bullet \bullet \bullet}$ & -.13 & .03 & $.15^{\bullet \bullet}$ & -.28 \\
\hline Small group & $.11^{\bullet}$ & .01 & .08 & -.10 & .08 \\
\hline Female groups & -.14 & .24 & -.13 & -.01 & -.06 \\
\hline Prior friendships & .06 & .00 & $-.11^{\bullet}$ & -.10 & -.02 \\
\hline Contribution to $R^{2}$ & .07 & .08 & .05 & .06 & .15 \\
\hline Amount of interaction & & & $-.24^{\bullet \bullet \bullet \bullet \bullet ~}$ & $.32^{\bullet \bullet \bullet \bullet ~}$ & $-.39 \bullet \bullet \bullet$ \\
\hline Interaction on TQM task & -.01 & .06 & & & \\
\hline Total memos sent & .07 & .05 & $.33^{\bullet \bullet \bullet \bullet}$ & .01 & - \\
\hline Contribution to $R^{2}$ & .00 & .01 & .16 & .08 & .11 \\
\hline Relational demography (RD) & .12 & $.58^{\bullet \bullet \bullet \bullet}$ & $.20^{\bullet \bullet}$ & .00 & .00 \\
\hline Organizational culture (OC) & .01 & $.18^{\bullet}$ & -.06 & $-.19^{\bullet \bullet \bullet}$ & .02 \\
\hline Contribution to $R^{2}$ & .00 & .16 & .02 & .03 & .00 \\
\hline $\mathrm{RD} \times \mathrm{OC}$ & $.31^{\bullet \bullet}$ & .03 & $.27^{\bullet \bullet}$ & $.37^{\bullet \bullet \bullet}$ & $.28^{\bullet \bullet}$ \\
\hline Contribution to $R^{2}$ & .02 & .00 & .01 & .02 & .02 \\
\hline$R^{2}$ & .14 & .26 & .28 & .22 & .30 \\
\hline Adjusted $R^{2}$ & .09 & .14 & .24 & .17 & .26 \\
\hline Overall F-ratio & $2.59^{\bullet \bullet \bullet \bullet ~}$ & $2.14^{\bullet \bullet}$ & $6.16^{\bullet \bullet \bullet \bullet ~}$ & $4.51^{\bullet \bullet \bullet \bullet ~}$ & $7.00^{\bullet \bullet \bullet \bullet ~}$ \\
\hline D.F. & 15,233 & 15,91 & 15,233 & 15,233 & 14,231 \\
\hline
\end{tabular}

$\bullet p<.10 ; \bullet p<.05 ;{ }^{\bullet \bullet} p<.01 ; \cdots \bullet p<.001$.

* Entries represent standardized coefficients and are reported in the order entered.

$1.130\left(x_{2}\right)+$ e. Thus, in contrast to our prediction, as similarity increased, those working in collectivistic cultures reached decisions on fewer tasks.

Table 3 (model 4) also shows results for our second measure of productivity, the amount of time it took subjects to complete the four tasks. While not predicted, organizational culture had a negative main effect, indicating that those in individualistic cultures took longer to complete tasks. The interaction term was also significant. The reduced equation for the individualistic culture slope analysis was

$y=15.475+-7.336\left(x_{2}\right)+e$, and for the collectivistic culture, $y=7.463+4.679\left(x_{2}\right)+e$. Corroborating the finding for the first productivity measure reported above, and in contrast to our prediction in $\mathrm{H} 3 \mathrm{~b}$, as demographic similarity to their coworkers increased, those in collectivistic cultures spent substantially less time on tasks than did those in individualistic cultures.

Finally, model 5 in table 3 shows the results for our third productivity measure, the total percentage of issues subjects addressed in the simulation. The variable "total memos sent" was not used as a control in this equation because of its overlap with the denominator of the dependent variable $(r=.60, p<.01)$. A significant interaction effect emerged. The slope analysis reduced equation for the individualistic culture was $y=0.272+-0.065\left(x_{2}\right)+e$, and for the collectiv-

770/ASO, December 1998 
istic culture, $y=0.240+0.039\left(x_{2}\right)+e$. As dissimilarity increased, the total percentage of issues dealt with decreased in individualistic cultures but increased in collectivistic cultures, a pattern consistent with the other two productivity variables but inconsistent with our prediction.

\section{Additional Analyses}

We conducted two types of additional analyses to rule out alternative explanations for the results reported above. First, it is possible that either personality alone or the fit between personality and organizational culture explains these work processes and outcomes. Therefore, we collected a measure of personal collectivism, modeled after Chatman and Barsade (1995), from a portion of this sample (one of the three instructors had collected personality data on 138 subjects a month before the simulation). We ran each of our analyses again two ways. First, we entered the personality measure of collectivism on the first step of the regression equations along with the demography variables. Second, we entered as control variables both personal collectivism and a dummy variable indicating whether a subject did or did not fit with the culture to which he or she was assigned. Thus, subjects received a zero, indicating misfit, if they were above the median on personal collectivism and were assigned to an individualistic culture or if they were below the median on personal collectivism and were assigned to a collectivistic culture. Conversely, subjects received a one, indicating fit, if they were above the median on personal collectivism and were assigned to a collectivistic culture or if they were below the median on personal collectivism and were assigned to an individualistic culture.

When controlling for personality or personality and fit, the same pattern of results emerged as those reported above except that some of the effects were slightly weaker, probably because of the reduced sample on which we had personality data. For example, the interaction effect for the dependent variable "total memos sent" remained significant, but slightly less so when personal collectivism and fit were controlled $(\beta=.36, p<.05$, d.f. $=15,117)$. Similarly, the interaction effect for the dependent variable "amount of interaction with coworkers" remained significant, although, again, less so when we controlled for personal collectivism and fit $(\beta=-.36, p<.05$, d.f. $=15,117)$. This pattern, in which the direction and magnitude of the standardized beta coefficients remain approximately the same but the significance levels decrease slightly, occurs repeatedly for the other dependent variables. Despite this reduced sample size, all of the tests of our hypotheses remained significant (at least at the .10 level) when we controlled for personal collectivism and the fit between personal collectivism and organizational culture.

We conducted an additional diagnostic test by rerunning each of our regression analyses without the data from the two all-female organizations, which we had included as a way of distinguishing between the salience of demographic categories based on numerical composition versus contextual norms. Being female was salient in these all-female groups which, on the surface, seems to contradict our hypothesis of homogeneity, reducing the salience of demo-

771/ASQ, December 1998 
graphic categories. Our pattern of results with and without the two all-female organizations included in the sample, however, was virtually identical: the beta coefficients were the same sign but were often slightly smaller and slightly less significant. The pattern of slightly smaller coefficients may be explained by the reduced sample size when the two all-female groups were removed (decreasing the sample size by 40 people, or 16 percent), rather than by substantive dif= ferences in individuals' behavior in a homogeneous group of "minority" members (relative to their presence in professional U.S. organizations). These additional analyses, combined with our inclusion in the original analyses of a dummy variable controlling for membership in all-female organizations, should eliminate differences in these two organizations as a viable alternative explanation for our results.

\section{DISCUSSION}

Our goal in this study was to determine whether an organization's relative focus on individualism or collectivism influenced whether coworkers would view one another as having interchangeable interests and a common fate by affecting the salience of organizational membership as a social category. We proposed that demographic differences would remain salient categories unless the organizational culture emphasized commonalties among members' interests and that a relative emphasis on individualism or collectivism would influence coworkers who were similar to one another differently than those who were different from one another. We began by focusing on how demography and culture influenced the social categorization process. We found that the salience of demographic attributes as social categories was higher in heterogeneous than homogeneous organizations only when we excluded sex from the demographic attribute scale. This may have been due to the two all-female simulated organizations since, even though they were more homogeneous than conditions in which sex was mixed, sex may have been more salient than in all-male organizations. This increased salience may be accounted for by the generally low incidence of all-female organizations, both in corporations and business schools (including this research site, in which 71 percent of students were male). Future research should distinguish between numerical distinctiveness and historical atypicality, as these appear to have different effects on the salience of social categories.

We also found that the salience of organizational attributes as social categories was higher in collectivistic than individualistic organizational cultures. Further, the salience of organizational and demographic categories were inversely related. Taken together, these results suggest that the extent to which a person is demographically similar or different from coworkers and an organization's cultural emphasis influence the social categorization process, a finding that has been assumed but not tested in prior research. These propositions set the stage for the primary focus of the study, considering the effects of diversity and culture on work processes and outcomes.

We examined two indicators of interpersonal interaction among coworkers. The number of memos sent had no sig-

772/ASQ, December 1998 


\section{Being Different}

nificant main effects, but the interaction showed that, as predicted, an emphasis on collectivism led to a greater increase in memo sending among diverse members than among members who were more similar to their coworkers. Interestingly, we found the opposite effect for our other measure of interaction. Members who were more similar to their coworkers were more influenced by their organization's focus on either individualism or collectivism. Thus, in contrast to our prediction, as similarity among coworkers increased, so did the number of people with whom collectivistic culture members met.

The differences in the pattern of results suggest that sending memos and meeting with others represent different types of interaction. Meetings and memos may be substitutes for one another, as indicated by their negative relationship. But if, as network researchers argue, the real work of an organization gets done through informal face-to-face interactions, sending memos may be less effective for conveying information and resolving problems (e.g., Krackhardt, 1992). One implication of this finding is that when people are more different from their coworkers they are more reluctant to interact in person and that an organizational culture that is sufficiently strong to cause differences in interaction among similar coworkers does not have such an effect when coworkers are different from one another. Coworkers who were different from one another were responsive to the organizational culture in sending memos, but they may have been comfortable participating in only a narrow range of types of interaction. Future research should compare how demographically similar and different people use a broader array of communication modes than were studied here.

$\mathrm{H}$ 2a predicted that more conflict would emerge when people were more demographically different from one another, but we found no difference between people working with similar and different coworkers. This may have been due to subjects' reluctance to report or acknowledge conflict, particularly when greater diversity existed, due to concerns over being politically correct (e.g., Brief et al., 1995). But, as predicted in $\mathrm{H} 2 \mathrm{~b}$, more conflict existed in individualistic than in collectivistic cultures. Further, as demographic similarity decreased, those working in collectivistic cultures experienced conflict as more beneficial than did those working in individualistic cultures, supporting $\mathrm{H} 2 \mathrm{c}$. Thus, members of individualistic cultures, whose goals and values probably varied more than the common goals among members of collectivistic cultures, experienced more conflict. Further, culture moderated the extent to which people who were different from their coworkers perceived conflict as beneficial. Conflict, which would otherwise be viewed as detrimental among diverse people, was perceived as beneficial when the organization emphasized collective outcomes. This finding has significant implications for making conflict more constructive for demographically diverse workers. Future research should investigate whether different behavioral manifestations of conflict emerged in the different conditions or whether the same behaviors were simply perceived differently in one context than the other. One remaining question, however, is whether beneficial conflict is perceived as similar to having 
less conflict, as suggested by the main effect for overall amount of conflict.

We found support for our creativity hypothesis (3a) for selfratings. Following our prediction, as similarity decreased, the impact of culture on creativity was greater, such that those in collectivistic cultures perceived themselves as more creative than did those in individualistic cultures. We did not find this significant interaction for the expert ratings, but the two significant main effects were consistent with the logic underlying our interaction hypothesis. Specifically, dissimilar people in collectivistic cultures had the highest creative output. This pattern was revealed by an interaction effect for self-reported creativity and by additive main effects for expert-rated creativity. Taken together, these results suggest that creativity emerges from the combination of (1) access to a larger set of novel ideas afforded by more diverse members and (2) trust that novel ideas will be used for the benefit of the collective. Thus, while we cannot offer an unequivocal resolution to past inconsistencies in research findings on the role of diversity in heightening or dampening creativity, these results suggest that future research should continue to consider the organizational context, such as an organization's degree of individualism or collectivism, when examining these issues.

Finally, the pattern of findings was consistent across the three productivity measures but inconsistent with our prediction in $\mathrm{H} 3 \mathrm{~b}$. Culture had more influence on productivity among coworkers who were demographically similar than among those who were more different from one another. Similar people were significantly more productive in individualistic than collectivistic cultures, while dissimilar people were similarly productive across the two cultures. Productivity may have decreased more among similar members of collectivistic cultures because less of their time interacting with one another was spent on task-related issues, and more may have been spent socializing. Thus, even though we controlled for the amount of interaction among members, the content of that interaction may have varied based on how similar people were to one another. Dissimilar members may have focused more consistently on tasks, as suggested by the significant main effect for relational demography on productivity, because they may have had fewer other topics in common to discuss with one another. This suggests that both the amount and content of interaction influence work outcomes. Future research might examine whether identical amounts of interaction have greater benefit among demographically similar coworkers, compared with homogeneous coworkers, because the task content is richer. Diverse people should have a wider variety of ideas to share and debate during their interaction, allowing them to realize greater returns for the time invested. Unfortunately, interaction among dissimilar people, while perhaps the most beneficial, also appears to be the most difficult to cultivate.

Interestingly, increased diversity was related to decreased interaction but to increased productivity. This could imply that the tasks themselves were more efficiently completed by individuals than by teams. We designed the four salient tasks to be completed either by individuals working alone or

774/ASQ, December 1998 
in groups, but since many of the issues embedded in the tasks were relevant to a large part of the organization, we expected coworker interaction to be at least somewhat beneficial. One possibility is that subjects who completed more tasks simply did not do them as well. A second possibility is that the benefit from interaction may have been attenuated if people interacted too much; that is, the discussions that make up social interaction may have carried over to many topics that were not relevant to the task that brought the people together to begin with. The negative relationship between face-to-face social interaction and productivity $(r=-.34, p<.001)$ may have been due to more discussion of irrelevant issues among similar people. Those who were more different from their coworkers, however, were also more productive, controlling for amount of social interaction. Thus, the negative relationship between social interaction and productivity does not explain the positive effect on productivity of being demographically different.

An alternative explanation is that meeting with other people may have had both a direct and an indirect negative effect on completing the four major tasks. The direct effect was that the time spent interacting about issues other than the four major tasks may have detracted from completing these tasks. The indirect effect was that interaction with others may have highlighted issues other than the four major tasks, so that when people did return to working alone they may have attended to these other issues. While the direct effect would be accounted for by the social interaction control variable, the indirect effect would not. Further, the idea that social interaction had an indirect negative effect on completing the four major tasks is consistent with the lack of effect of being different on the variable "percent of total issues dealt with." This lack of effect suggests that when considering all issues, people completed the same percent regardless of their similarity to others. Thus, social interaction may have caused people to attend to more issues, decreasing their productivity on the four major tasks but not affecting their productivity when considering all tasks.

Despite the value of a simulation for increasing control over demographic and cultural patterns, generalizations from this study are limited by our approach. Our sample consisted of MBA students, who may be somewhat unrepresentative of organizational employees in the U.S. In particular, our subjects were likely to be younger, wealthier, and more educated than the working population. Ironically, one way that this sample may have biased our results was to increase the conservativeness of our tests. Business school students should be less prone to inappropriate discrimination, or at least more attuned to behaving in a politically correct manner (Brief et al., 1995). Further, the school had recently ranked extremely highly on the Business Week Business School Rankings, which would be expected to create a sense of pride and a common bond among the students (e.g., Elsbach and Kramer, 1995). Taken together, one would expect these students to attempt to be open and able to work with any of their classmates, regardless of their demographic differences. And yet we found substantial variance in work processes and outcomes even among individuals who were

775/ASQ, December 1998 
more homogeneous on some dimensions than members of the work force at large. Future studies should examine these issues in work organizations, using broader samples of employees to enhance representativeness and to include other potentially important relational demography characteristics, such as tenure and functional background.

Future research might also reconsider our relational demography measure, as we aggregated across multiple demographic categories. Each demographic attribute may have different effects in different contexts and certain minority groups may use their networks in different ways and have differential access to members of other demographic groups based on structural constraints (e.g., Ibarra, 1992). Future researchers should attempt to understand the relative importance of different demographic attributes in various situations (e.g., Riordan and Shore, 1997). A related issue is that our focus was on situations in which all members of an organization were either relatively similar to one another or relatively different from one another, but the moderating effects of culture on diversity may relate differently to different patterns of diversity. Future research should examine the effects of culture on different demographic patterns among members, such as when smaller numbers of people are more demographically different than are others in an organizational setting.

Our simulation also simplified a number of complexities that exist in real organizations. For example, culture established in a short-term simulation is not the same as a firm's ongoing culture. Organizational cultures are more ambiguous than the culture we manipulated (e.g., Meyerson, 1994). Ironically, such ambiguity may result from the greater cultural information to which real employees would have access. For example, inconsistencies between the purported culture and the actual culture may be greater to the extent that employees observe differences between what leaders say and what they do. The simulation approach was valuable given the difficulty of finding pure field analogs of firms that only vary on the individualism-collectivism dimension. But organizational culture is multifaceted, and a variety of important dimensions may be salient simultaneously or emerge at different times (e.g., Chatman and Jehn, 1994). Also, culture may be linked to strategic and structural differences among firms, variables that we essentially held constant in this study. Variations in culture, strategy, and structure may cause jobs to be defined differently and human resource practices to vary. Such variations may even affect the incidence with which the combinations of demographic diversity and type of culture actually occur. For these reasons, future research should examine the moderating effects of culture on demographic diversity in real firms.

Despite these limitations, our results suggest that social categorization may be a linking mechanism between various attributes and behaviors influencing work processes and outcomes, though the extent to which the salience of various categories is context-dependent increases the complexity of these links (Oakes, 1987). We found some support for the relationship between demographic and organizational attributes and the salience of the associated categories, but much

776/ASQ, December 1998 
work remains to verify these and to identify other contextual factors that influence the relationship between social categorization and behavior.

One contribution of this study is the focus on specific differences in how demographically diverse members interact and work. For example, increased diversity was related to decreased interaction but also to increased productivity. A second contribution is a better understanding of the effects of individualistic and collectivistic cultures. Less conflict and more interaction occurred in collectivistic cultures, but less time was spent on tasks. The most important findings emerged from interactions between demography and culture, suggesting that each has different effects on work processes and outcomes. Some of the negative factors emerging in firms with greater diversity may be minimized by increasing the extent to which membership with the organization and members' sense of shared fate is made salient. Conflict was seen as more beneficial and creativity was enhanced more in heterogeneous organizations when the organization emphasized collectivism. The study also shows that many challenges remain for managers, such as reduced interaction and a reduced willingness to share ideas among diverse members. Interestingly, rather than collectivistic cultures enabling the positive effects from diversity to emerge, for example, by encouraging people to work together, the individualistic culture may actually account for the effects found here. Organizations that promote individualistic values may be inadvertently prohibiting the positive effects that would otherwise arise from having diverse members.

Organizations may want to consider ways of enhancing members' sense of shared values and a common fate. Developing a more collectivistic culture may be accomplished by drawing from the means we used to establish our cultural conditions in the simulation. For example, top executives could develop a statement of values emphasizing the common good and behave in accordance with it. One reason why our culture manipulation might have been so clearly perceived was because there was no evidence of inconsistencies between stated values and actual behavior at the top. Since the president was not actually present, his or her behavior could not be viewed as contradicting the espoused culture. Thus, members had to rely on what was said rather than what was done. Organizations may also increase collectivism by basing part of employees' compensation on organizational outcomes and by collecting performance feedback from a variety of people who work with the focal individuals, which would tie members to one another and the organization (e.g., Chatman, Schnog, and Spataro, 1998). Further, research has shown that cultures are formed and maintained through rituals and celebration (e.g., Trice and Beyer, 1984), and celebrating team successes on a regular basis may thus contribute to a sense of shared fate. As for diversity, our conclusion is quite straightforward. Given the demographic changes occurring now and in the near future, and given the strong employment rate, most organizations will have no choice but to integrate diverse people into their organizations. A collectivistic emphasis may help to increase the effectiveness of diverse people working together.

777/ASO, December 1998 


\section{Allport, Gordon W.}

1954 The Nature of Prejudice. Cambridge, MA: Addison-Wesley.

\section{Amabile, Theresa $M$.}

1988 "A model of creativity and innovation in organizations." In B. M. Staw and L. L. Cummings (eds.), Research in Organizational Behavior, 10: 123-168. Greenwich, CT: JAI Press.

Arrow, Holly, and Joseph E.

\section{McGrath}

1993 "Membership matters: How member change and continuity affect small group structure, process and performance." Small Group Research, 24: 334-361.

\section{Axelrod, Robert}

1984 The Evolution of Cooperation. New York: Basic Books.

Boulding, Kenneth

1963 Conflict and Defense. New York: Harper \& Row.

Brewer, Marilynn B.

1979 "In-group bias in the minimal intergroup situation: A cognitive-motivational analysis." Psychological Bulletin, 86: 307-324.

1981 "Ethnocentrism and its role in interpersonal trust." In M. B. Brewer and B. E. Collins (eds.), Psychology of Intergroup Relations: 141-183. Chicago: Nelson-Hall.

Brief, Arthur P., Robert T. Buttram, Jodi D. Elliott, and Robin M. Reizenstein

1995 "Releasing the beast: A study of compliance with orders to use race as a selection criterion." Journal of Social Issues, 51: 177-193.

Chatman, Jennifer A., and Sigal G. Barsade

1995 "Personality, organizational culture, and cooperation: Evidence from a business simulation." Administrative Science Quarterly, 40: 423-443.

Chatman, Jennifer A., and Karen A. Jehn

1994 "Assessing the relationship between industry characteristics and organizational culture: How different can you be?" Academy of Management Journal, 37: 522-553.
Chatman, Jennifer A., Karen A. Schnog, and Sandra A. Spataro 1998 "Getting people to cooperate: The influence of personality, formal and informal incentives, and being different." Working paper, University of California, Berkeley.

Cohen, Jacob, and Patricia Cohen

1983 Applied Multiple Regression/ Correlation Analysis for the Behavioral Sciences, 2d ed. Hillsdale, NJ: Erlbaum.

Cox, Taylor H., Sharon A. Lobel, and Poppy L. McLeod

1991 "Effects of ethnic group cultural differences on cooperative and competitive behavior on a group task." Academy of Management Journal, 34: 827-847.

\section{Donnellon, Anne}

1993 "Crossfunctional teams in product development: Accommodating the structure to the process." Journal of Product Innovation Management, 10: 377-392.

Earley, P. Christopher

1993 "Social loafing and collectivism: A comparison of the United States and the People's Republic of China." Administrative Science Quarterly, 34: 565-581.

Elsbach, Kimberly D., and Roderick M. Kramer

1995 'Members' responses to organizational identity threats: Encountering and countering the Business Week rankings. Administrative Science Quarterly, 41: 442-476.

Gruenfeld, Deborah H., Elizabeth

A. Mannix, Katherine Y. Williams, and Margaret $A$. Neale

1996 "Group composition and decision making: How member familiarity and information distribution affect process and performance." Organizational Behavior and Human Decision Processes, 67: 1-15.

Guzzo, Richard A., and Marcus W. Dickson

1996 "Teams in organizations: Recent research on performance and effectiveness." Annual Review of Psychology, 47: 307-338.
Heilman, Madeline E.

1994 "Affirmative action: Some unintended consequences for working women." In B. M. Staw and L. L.Cummings (eds.), Research in Organizational Behavior, 16: 125-170 Greenwich, CT: JAI Press.

Hoffman, L. Richard

1979 "Applying experimental research on group problem solving to organizations." Journal of Applied Behavioral Science, 15: 375-391.

Hoffman, L. Richard, and Norman

R. F. Maier

1961 "Quality and acceptance of problem solutions by members of homogeneous and heterogeneous groups." Journal of Abnormal and Social Psychology, 62: 401-407.

Ibarra, Herminia

1992 "Homophily and differential returns: Sex differences in network structure and access in an advertising firm." Administrative Science Quarterly, 37: 422-447.

Jaccard, James, Robert Turrisi, and Choi K. Wan

1990 "The case of a qualitative moderator and a continuous variable." Interaction Effects in Multiple Regression: 42-48. Newbury Park, CA: Sage.

\section{Jackson, Susan}

1992 "Team composition in organizations." In S. Worchel, W. Wood, and J. Simpson (eds.), Group Process and Productivity: 138-173. London: Sage.

Jehn, Karen A.

1995 "A multimethod examination of the benefits and detriments of intragroup conflict." Administrative Science Quarterly, 40: 256-282.

Kanter, Rosabeth $\mathrm{M}$.

1977 Men and Women of the Corporation. New York: Basic Books.

1991 "Transcending business boundaries: 12,000 world managers view change." Harvard Business Review, MayJune: 151-164. 


\section{Krackhardt, David}

1992 "The strength of strong ties: The importance of Philos in organizations." In Nitin Nohria and Robert G. Eccles (eds.), Networks and Organizations: 216-239. Boston: Harvard Business School Press.

Kramer, Roderick M., Marilynn B. Brewer, and Benjamin A.

Hanna

1996 "Collective trust and collective action: The decision to trust as a social decision." In R. M. Kramer and T. R. Tyler (eds.), Trust in Organizations: Frontiers of Theory and Research: 357-389. Thousand Oaks, CA: Sage.

Lombardo, Michael M., Morgan W. McCall, Jr., and David L.

\section{DeVries}

1989 University Edition Looking Glass Inc. Instructors Manual. Greensboro, NC: Center for Creative Leadership.

Markus, Hazel R., and Susan

Cross

1990 "The interpersonal self." In L. A. Pervin (ed.), Handbook of Personality: Theory and Research: 576-608. New York: Guilford Press.

Markus, Hazel R., and Shinobu

Kitayama

1991 "Culture and the self: Implications for cognition, emotion, and motivation." Psychological Review, 98: 224-253.

Messick, David M., and Diane M. Mackie

1989 "Intergroup relations." Annual Review of Psychology, 40: 45-81.

Meyerson, Debra

1994 "Interpretations of stress in institutions: The cultural production of ambiguity and burnout." Administrative Science Quarterly, 39: 628653.

Nemeth, Charlan

1986 "Differential contributions of majority and minority influence." Psychological Review, 93: 23-32.

1992 "Minority dissent as a stimulant to group performance." In S. Worchel, W. Wood, and J. Simpson (eds.), Group Process and Productivity: 95-111. London: Sage.
Oakes, Penelope J.

1987 "The salience of social categories." In J. C. Turner (ed.), Rediscovering the Social Group: A Self-Categorization Theory: 117-141. Oxford: Basil Blackwell.

O'Reilly, Charles A., David F. Caldwell, and William P. Barnett

1989 "Work group demography, social integration, and turnover." Administrative Science Quarterly, 34: 21-37.

O'Reilly, Charles A., and Jennifer

A. Chatman

1996 "Culture as social control: Corporations, cults, and commitment." In B. M. Staw and L. L. Cummings (eds.), Research in Organizational Behavior, 18: 157-200. Greenwich, CT: JAI Press.

Pfeffer, Jeffrey

1983 "Organizational demography." In L. L. Cummings and B. M. Staw (eds.), Research in Organizational Behavior, 5: 299357. Greenwich, CT: JAI Press.

Riordan, Christine M., and Lynn McFarlane Shore

1997 "Demographic diversity and employee attitudes: An empirical examination of relational demography within work units." Journal of Applied Psychology, 82: 342358.

Shah, Priti, and Karen A. Jehn

1993 "Do friends perform better than acquaintances? The interaction of friendship, conflict, and task." Group Decision and Negotiation, 2: 149-166.

Sherif, Muzafer, O. J. Harvey, B. Jack White, William R. Hood, and Carolyn W. Sherif

1961 Intergroup Conflict and Cooperation: The Robbers Cave Experiment. Norman, OK: Institute of Group Relations.

Simon, Herbert A.

1976 Administrative Behavior: A Study of Decision-Making Processes. New York: Free Press.

Stasser, G., and D. Stewart

1992 "Discovery of hidden profiles by decision-making groups: Solving a problem versus making a judgment." Journal of Personality and Social Psychology, 63: 426-434.
Taylor, Shelly E., and Susan Fiske 1978 "Salience, attention, and attribution: Top of the head phenomena." In L. Berkowitz (ed.), Advances in Experimental Social Psychology, 11: 249-288. New York: Academic Press.

Thomas, David A., and Robin J. Ely

1996 "Making differences matter: A new paradigm for managing diversity." Harvard Business Review, 74: 79-90.

Triandis, Harry C.

1995 Individualism and Collectivism. Boulder, CO: Westview.

Trice, Harrison M., and Janice M. Beyer

1984 "Studying organizational cultures through rites and ceremonials." Academy of Management Review, 9: 653-669.

1993 The Cultures of Work Organizations. Englewood Cliffs, NJ: Prentice Hall.

Tsui, Anne S., Terri D. Egan, and Charles A. O'Reilly

1992 "Being different: Relational demography and organizational attachment." Administrative Science Quarterly, 37: 549-579.

Tsui, Anne S., and Charles A.

O'Reilly

1989 "Beyond simple demographic effects: The importance of relational demography in superior-subordinate dyads." Academy of Management Journal, 32: 402-423.

Turner, John C.

1985 "Social categorization and the self concept: A social cognitive theory of group behavior." Advances in Group Processes, 2: 77-121. Greenwich, CT: JAI Press.

Turner, John C., Michael A. Hogg, Penelope J. Oakes, and Stephen D. Reicher

1987 Rediscovering the Social Group: A Self-Categorization Theory. New York: Basil Blackwell.

Turner, John C., Penelope J.

Oakes, S. Alexander Haslam, and Craig McGarty

1994 "Self and collective: Cognition and social context." Personality and Social Psychology Bulletin, 20: 454-463.

Tushman, Michael L.

1977 "Special boundary roles in the innovation process." Administrative Science Quarterly, 22: 587-605. 
Wagner, John A., III

1995 "Studies of individualism-collectivism: Effects on cooperation in groups." Academy of Management Journal, 38: 152-172.

Wagner, Ulrich, Ludger Lampen, and Jorg Syllwasschy

1986 "In-group inferiority, social identity and out-group devaluation in a modified minimal group study." British Journal of Social Psychology, 25: 1523.
Watson, Warren E., Kamalash Ku-

mar, and Larry K. Michaelsen

1993 "Cultural diversity's impact on interaction process and performance: Comparing homogeneous and diverse task groups." Academy of Management Journal, 36: 590602.

Wilder, David A.

1986 "Social categorization: Implications for creation and reduction of intergroup bias." Advances in Experimental Social Psychology, 19: 291-355.
Williams, Katherine $Y_{\text {., and }}$ Charles A. O'Reilly

1998 "Forty years of diversity research: A review." In B. M. Staw and L. L.Cummings (eds.), Research in Organizational Behavior, 20: 77-140. Greenwich, CT: JAI Press.

Zenger, Todd R., and Barbara S. Lawrence

1989 "Organizational demography: The differential effects of age and tenure distributions on technical communication." Academy of Management Journal, 32: 353-376. 